\title{
Editorial Special Issue: Caring for Children Outside the Home - From Institutions to Nations
}

\author{
Katie Barclay \\ University of Adelaide
}

This special issue began its life in 2015 in a series of workshops funded by the University of Adelaide that ran under the theme 'Dis/located Children: Children in/and Care'. The goal of the workshops was to take seriously the concept of 'care' as it applied to the lives of children. The workshops had a particular focus on childhoods that were in some sense beyond the normative, whether that was migrant or refugee children adapting to a new culture, children who lived outside the nuclear household, or children whose identities marked them as 'different'. They were underpinned by developments in both childhood and emotions studies that seek to destabilise the 'naturalness' of both childhood and emotion by exploring the ways that both are contingent, shaped by culture, and situated in historical time (Davin, 1999; Rosenwein, 2010). Over four events, the workshops brought together over 40 scholars and practitioners from a variety of disciplines, including history, literature, gender studies, law, education, social work, and psychology. The articles brought together in this special issue reflect this diversity of disciplinary approach.

As a variety of scholars have pointed out, the term 'care' is useful because it incorporates not just the practices of caring behaviours, but an emotional dimension (Held, 2006; Tronto, 2013). Indeed, some scholars have gone so far as to suggest that physical forms of care that were not accompanied by appropriate caring feelings may be deficient as care (Noddings, 2003). Yet, what exactly is meant by 'care', and what feelings should be associated with it, are topics of considerable discussion. Some theorists have ignored the question altogether, allowing for common-sense understandings of care to be applied. Others have focussed on principles or features of caring, such as the fulfilment of needs, the impact for power relationships, or the significance of care as a way of being in the world (Held, 2006; Monchinski, 2010). One of the difficulties of this for practitioners in caring services is that a lack of definition makes it difficult to ap- ply care in practice. Moreover, as a considerable focus on care has been on parents, and particularly mothers, as a model for caring ethics, what the care that institutions, service providers and similar organisations should look like is not always obvious. Indeed, much of the focus on institutional care has been on abuse prevention, rather than actively imagining what the best practice in caring might look like.

In this special issue, a number of articles explore what care looks like in practice. Highlighting the ways that care has differed over the centuries, Walker seeks to flesh out both the practices of care and its emotional dimensions in 17th-century English convents; Barclay, Michell, and Due ask service providers working with young people in contemporary South Australia how they define and apply care in their working practices; Due and Riggs compare how teachers and migrant and refugee children articulate care in the classroom; Cartmel and Hayes survey the literature on after-school care, seeking to understand how it is defined and how it is situated as a core area of academic concern; and Purtell and Mendes explore the significance of caring support in the process of transition into the adult world with young care leavers in Victoria. Whilst discussing care in a range of different out-of-home contexts, the papers show a marked agreement in the importance of providing practical supports, including ensuring basic needs are met, offering food, actively supporting and guiding relationships with other young people and other adults, as well as offering education and emotional support.

Where there is more variation over time is in attitudes towards childhood autonomy. The function of early modern convent care was to create good wives and mothers or obedient nuns. In a patriarchal society, such roles required an ability to sublimate the self to the needs of others, and so there was less emphasis on what girls wanted or in shaping autonomous female identities. In contrast, all the 
modern studies highlight the significance of personalised supports and providing space for the individual child to develop. Moreover, as Due and Riggs demonstrate, this is also something that modern children want and appreciate - an opportunity to tell their stories and be known. As this suggests, the forms of care with which children are provided are implicated in the making of particular forms of subjectivity and of citizens. As Kelly highlights in his article, it is the possibilities of care as a disciplining mechanism, as well as an enabler, that have often motivated governments and states to take an interest in caring for children. Education has been key here, not only providing children with important skills and voice, but shaping the child-subject, constraining them as 'dangerous subjects' and forming them as unproblematic citizens.

In similar ways, the management of the migrant and refugee child can be viewed as caring that is designed to support the needs of the state. The children studied by Due and Riggs are provided with care to enable greater integration of migrant and refugee families, as well as to enable a smoother transmission of such children into mainstream education. This arguably benefits the child, but is nonetheless an act of disciplining subjects to ensure the stability of the wider polity. Much more troubling is Agutter's historical study of mid-century migrants and refugees that highlights how children were removed from mothers and placed into institutions, foster care, or adoption as they interfered with their mother's capacity to find and take work. Processes of care and education, then, are deeply implicated in producing not just successful adults, but those who will not be a burden to the state. A parallel can be seen in Cartmel's discussion of after-school care, where attention to the types of care and education provided in such settings are justified due to their importance in promoting health, reducing obesity, and otherwise producing successful adults. 'Highquality' care in this instance becomes collapsed into forms of care that produce high-functioning children and adults, and where care, the needs of the child and the needs of the state become connected.

Through such processes, caring for children becomes implicated in the making not just of healthy and successful adults, but in shaping polities, societies, and nations. Children are made into economic and political agents, who are increasingly entitled to a voice but not to disrupt what it might mean to be a successful adult. They are given space - and want a space - to give voice to their 'true' selves (see Barclay, Michell, \& Due; Due \& Riggs in this issue), but such selves must not disrupt service providers or systems of education. The child is therefore taught to voice a bounded self that is suitable for the polity that cares for it.

As this suggests, and is well-recognised in the literature, care is deeply implicated in power relationships (Tronto, 1993). The concept of care is perhaps particularly associated with children. It is notable that despite a range of official terminology in different places, children looked after by the state are colloquially described as being 'in care' in both the
UK and Australia; language that is not typically applied to adults who may also be under the guardianship of the state. The specific vulnerabilities of childhood, and especially the early years that require children to be actively cared for in order to survive and flourish, ensure that care cannot be considered an exceptional experience for the young, as it has at times been for adults (Kittay \& Feder, 2003). Childhood, then, has often been viewed as a period of dependency and the ways that such dependencies have implicated children in systems of power are well recognised and critiqued (Zelizer, 1994). As Kelly notes, new imaginings of childhood have tried to empower children as agents with (at least some) capacity to speak for themselves, a movement that has flourished in education, in particular.

Yet, as both Barclay, Michell, and Due, and Purtell and Mendes argue, the disjuncture between the desire, particularly amongst young people, for personal autonomy and their need for often quite structured supports in practice remains a constant site of tension. Where is the space in caring practices for the child's agency, especially given that caring has become so implicated in making particular types of citizens? How should one care for the rebellious child, the child who claims another language or culture as their birth right, the child who refuses to conform to broader educational structures? And how does that sit alongside the need for care of children to also protect them from harms, including those potentially produced by their own decisionmaking?

The authors who have participated in this special issue do not provide the answers to these questions, but they do begin to open up a discussion about how the care children receive from institutions, service providers, and similar organisations becomes implicated in larger structures of power. It has long been recognised that the care provided by institutions and the state embedded children and adults into relationships of power that could ultimately be harmful and destructive. Yet, very often our approach to such situations has been to deny that such action was care, that it was entitled to use such language. Amongst ethicists who promote care as way of being in the world, care is placed into a model of kindness, cooperation, and working to better each other (Held, 2006). But such theories have often failed to interrogate the ways that care is also implicated in socialisation and the production of identities, perhaps especially for children. This comes into particularly sharp definition when care beyond the home becomes the object of study.

The articles in this special issue are complemented by two commentaries that explore ways that care could change and is changing today. Ainsworth and Hansen summarise amendments to procedure around adoption in New South Wales and explore some of the possible implications; Korr highlights the contradictions in policy and practice when applying children's rights in a context of residential mental health service provision. Both are useful reminders of the opportunities and places where caring for children can 
be, and are being, reimagined. This issue is also accompanied by two book reviews. Together, the authors in this special issue seek to bring light to the practices and imaginings of out-of-home care across time and space, and to demonstrate not only its historical and contingent nature but its embeddedness within wider social and political structures.

\section{References}

Davin, A. (1999). What is a child? In A. Fletcher \& S. Hussey (Eds.), Childhood in question: Children, parents and the state (pp. 15-36). Manchester: Manchester University Press.

Held, V. (2006). The ethics of care: Personal, political, global. Oxford: Oxford University Press.
Kittay, E. F., \& Feder, E. K. (Eds.) (2003). The subject of care: Feminist perspectives on dependency. Lanham, MD: Rowman \& Littlefield.

Monchinski, T. (2010). Education in hope: Critical pedagogies and the ethics of care. New York: Peter Laing.

Noddings, N. (2003). Caring: A feminine approach to ethics and moral education. Berkeley: University of California.

Rosenwein, R. (2010). Problems and methods in the history of emotions. Passions in Context, 1(1), 1-32.

Tronto, J. C. (1993). Moral boundaries: A political argument for an ethic of care. Routledge: London.

Tronto, J. C. (2013). Caring democracy: Markets, equality, and justice. New York: New York University Press.

Zelizer, V. (1994). Pricing the priceless child: The changing social value of children. Princeton: Princeton University Press. 